\section{Trajetória da política de controle do tabaco no Brasil de 1986 a 2016}

\author{
History of Brazil's tobacco control policy from \\ 1986 to 2016
}

\section{Trayectoria de la política de control al tabaco en Brasil de 1986 a 2016}

Leonardo Henriques Portes 1,2 Cristiani Vieira Machado 2

Silvana Rubano Barretto Turci 2

doi: 10.1590/0102-311X00017317

\section{Resumo}

O estudo analisa a politica brasileira de controle do tabaco entre 1986 e 2016, buscando caracterizar a trajetória da politica e discutir os seus avanços, limites e desafios. Adotaram-se a perspectiva da economia politica e contribuições do referencial de análise de políticas públicas. Realizou-se análise bibliográfica, documental, de dados secundários e de entrevistas semiestruturadas com atores envolvidos na política. Fatores relacionados ao contexto nacional e internacional, ao processo político e ao conteúdo da política influenciaram a institucionalidade do controle do tabaco no país. Ressaltam-se a consolidação da rejeição social ao tabagismo, a estruturação governamental da politica, a atuação da sociedade civil e o prestígio do Brasil no cenário internacional. Medidas intersetoriais de controle do tabaco, como o aumento de preços e impostos de cigarros, a promoção de ambientes livres do fumo e a adoção de advertências sobre os malefícios do tabagismo contribuíram para a expressiva redução da prevalência de fumantes no período. A implementação da Convenção-Quadro para Controle do Tabaco da Organização Mundial da Saúde no Brasil, a partir de 2006, contribuiu para a expansão e consolidação da politica nacional. No entanto, interesses econômicos relacionados ao tabaco limitaram a implementação de algumas ações estratégicas. Entre os desafios, destacam-se a sustentabilidade do controle do tabaco a médio e longo prazos e a superação das barreiras relacionadas à diversificação em áreas plantadas de fumo, ao combate ao comércio ilícito de cigarros e à interferência da indústria do fumo na política.

Tabaco; Programa Nacional de Controle do Tabagismo; Politicas Públicas de Saúde

\section{Correspondência}

L. H. Portes

Policlínica Piquet Carneiro, Universidade do Estado do Rio de Janeiro.

Av. Marechal Rondon 381, Rio de Janeiro, RJ 20950-003, Brasil.

leo.portes@yahoo.com.br

1 Universidade do Estado do Rio de Janeiro, Rio de Janeiro, Brasil.

2 Escola Nacional de Saúde Pública Sergio Arouca, Fundação Oswaldo Cruz, Rio de Janeiro, Brasil. 


\section{Introdução}

O tabagismo é a principal causa de mortes prematuras evitáveis no mundo. A Convenção-Quadro para o Controle do Tabaco da Organização Mundial da Saúde (CQCT-OMS), em vigor desde 2005, tem contribuído para a redução da prevalência de fumantes. Porém, a indústria do tabaco é uma grande ameaça à contenção do tabagismo 1 .

Apesar de ser o segundo maior produtor e o maior exportador de fumo do mundo, o Brasil é uma referência internacional no controle do tabaco. A Política Nacional de Controle do Tabaco (PNCT) é reconhecida como uma política de Estado que envolve diversas ações intersetoriais 2.

Na década de 1960, observam-se as primeiras iniciativas de controle do tabaco no país, sendo elaborados projetos de lei visando à restrição da propaganda do tabaco e à impressão de advertências sobre os riscos à saúde 3 . Nas décadas seguintes, destacaram-se a elaboração da Carta de Salvador e do Programa Nacional Contra o Fumo em 1979, a realização da 1ạ Conferência Brasileira de Combate ao Tabagismo em 1980 e a formação do Grupo Assessor para o Controle do Tabagismo em 19854.

A partir de meados dos anos 1980, observou-se o fortalecimento da política de controle do tabaco no Brasil, caracterizada por: envolvimento de diferentes atores governamentais e não governamentais; adoção de medidas baseadas em evidências; descentralização de medidas; consolidação de uma base política, legislativa e institucional; e articulação com o contexto internacional 5 .

Este estudo buscou analisar a trajetória da política brasileira de controle do tabaco de 1986 a 2016 e os seus avanços, limites e desafios.

\section{Metodologia}

O estudo partiu de uma abordagem da economia política, ao valorizar as dimensões social, econômica e de poder da política de saúde 6 . Também foram consideradas contribuições do referencial da análise de políticas públicas 7 e do institucionalismo histórico 8 , ao ressaltar a importância das instituições que influenciam a estratégia dos atores, as agendas governamentais, as continuidades e as mudanças na política.

As estratégias metodológicas envolveram a análise documental de leis, normas e publicações, bem como das atas de 36 reuniões da Comissão Nacional para Implementação da Convenção-Quadro para o Controle do Tabaco (CONICQ), realizadas entre 2003 e 2014. Em 2015, realizou-se a observação direta da 1a Reunião Aberta da CONICQ e da Oficina dos dez anos da CQCT-OMS no Brasil, realizadas em Brasília. No mesmo ano, realizaram-se vinte entrevistas semiestruturadas com atores da PNCT: 14 dirigentes e técnicos federais cujos órgãos compõem a CONICQ (identificados como DTF 1-14); três representantes da sociedade civil apoiadoras da PNCT (SC 1-3); dois Deputados Federais (Leg. 1-2) e um representante do Secretariado da CQCT-OMS (Sec. CQCT-OMS). Analisaram-se, ainda, as respostas por e-mail de um representante da sociedade civil vinculado à indústria do tabaco (SCI). Os entrevistados foram selecionados a partir do seu envolvimento na formulação, gestão ou implementação da política nacional de controle do tabaco durante o período estudado. As entrevistas abordaram a contextualização da política brasileira no cenário internacional do controle do tabaco e a trajetória histórica, formulação e gestão da política, sendo utilizado um roteiro adaptado para cada entrevistado. Todos os entrevistados assinaram um Termo de Consentimento Livre e Esclarecido. Utilizou-se o gerenciador OpenLogos (http://openlogos.sourceforge.net/) para processamento das entrevistas.

O projeto de pesquisa foi aprovado pelo Comitê de Ética em Pesquisa da Escola Nacional de Saúde Pública Sergio Arouca, Fundação Oswaldo Cruz, sob o Certificado de Apresentação para Apreciação Ética no 42862915.5.0000.5240. 


\section{Resultados}

\section{Trajetória da política brasileira de controle do tabaco}

No século XX, até os anos 1980, houve regulamentações esparsas relacionadas aos aspectos econômicos do tabaco (Figuras 1 e 2). Entre 1986 e 2016, a política brasileira de controle do tabaco se estruturou e se expandiu, compreendendo diversas estratégias que contribuíram para uma significativa redução da prevalência do tabagismo (Figura 3; Tabela 1). Identificaram-se três diferentes momentos, caracterizados segundo o contexto, processo e conteúdo da política: estruturação inicial da política (1986-1998); negociações da CQCT-OMS e sua ratificação pelo Brasil (1999-2005); e implementação da CQCT-OMS no país (2006-2016).

\section{- Estruturação inicial da política (1986-1998)}

Na segunda metade da década de 1980, o Brasil vivia a redemocratização e a articulação do movimento sanitário, com a ampliação dos debates sobre os direitos sociais e a saúde 9 . Esse período também foi marcado pela valorização do controle do tabaco no cenário internacional. A criação do Dia Mundial sem Tabaco, em 1987, e a abordagem do tema em eventos internacionais fortaleceram esse processo. Intensificou-se a discussão sobre a necessidade de um tratado internacional voltado para o controle do tabaco.

As organizações médicas e o Instituto Nacional de Câncer (INCA), com o apoio da mídia, foram fundamentais para a conscientização da sociedade sobre os malefícios do tabagismo por meio de campanhas. Sob a liderança do INCA, observou-se a estruturação de uma rede envolvendo agências internacionais, órgãos governamentais e sociedade civil. Ações em escolas, unidades de saúde e ambientes de trabalho foram estratégicas no processo de descentralização do controle do tabaco no país.

Entre as iniciativas no período, destacam-se, em 1986, a criação do Programa Nacional de Combate ao Fumo (PNCF) e o estabelecimento do Dia Nacional de Combate ao Fumo. Nos anos seguintes, observam-se as primeiras normas relativas à inclusão de advertências nos maços de cigarro e nos

\section{Figura 1}

Evolução do número de instrumentos legislativos relacionados ao tabaco, por tema principal e década. Brasil, 1900-2016.
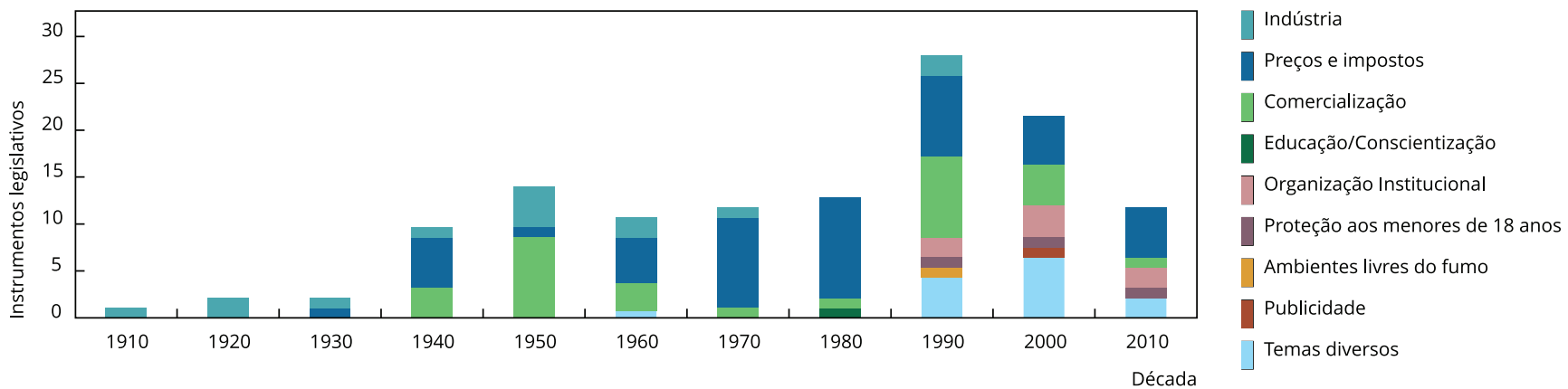

Fonte: elaborado pelos autores, a partir de diversas fontes: Saúde Legis (http://portal2.saude.gov.br/saudelegis/LEG_NORMA_PESQ_CONSULTA.CFM); Sistema de Informações do Congresso Nacional - Senado Federal (http://legis.senado.gov.br/sicon/); e Portal da Legislação - Presidência da República (http://www4.planalto.gov.br/legislacao).

Nota: (1) as legislações quantificadas envolvem leis, decretos, emendas constitucionais e medidas provisórias, e correspondem aos resultados da busca de publicações contendo, pelo menos, um dos termos: cigarro, fumo, tabaco e tabagismo. Não necessariamente correspondem a medidas de controle do tabaco; (2) a categoria "Temas diversos" refere-se às publicações que envolvem mais de uma das demais categorias. 
Figura 2

Evolução do número de instrumentos normativos relacionados ao tabaco, por tema principal e década. Brasil, $1900-2016$.

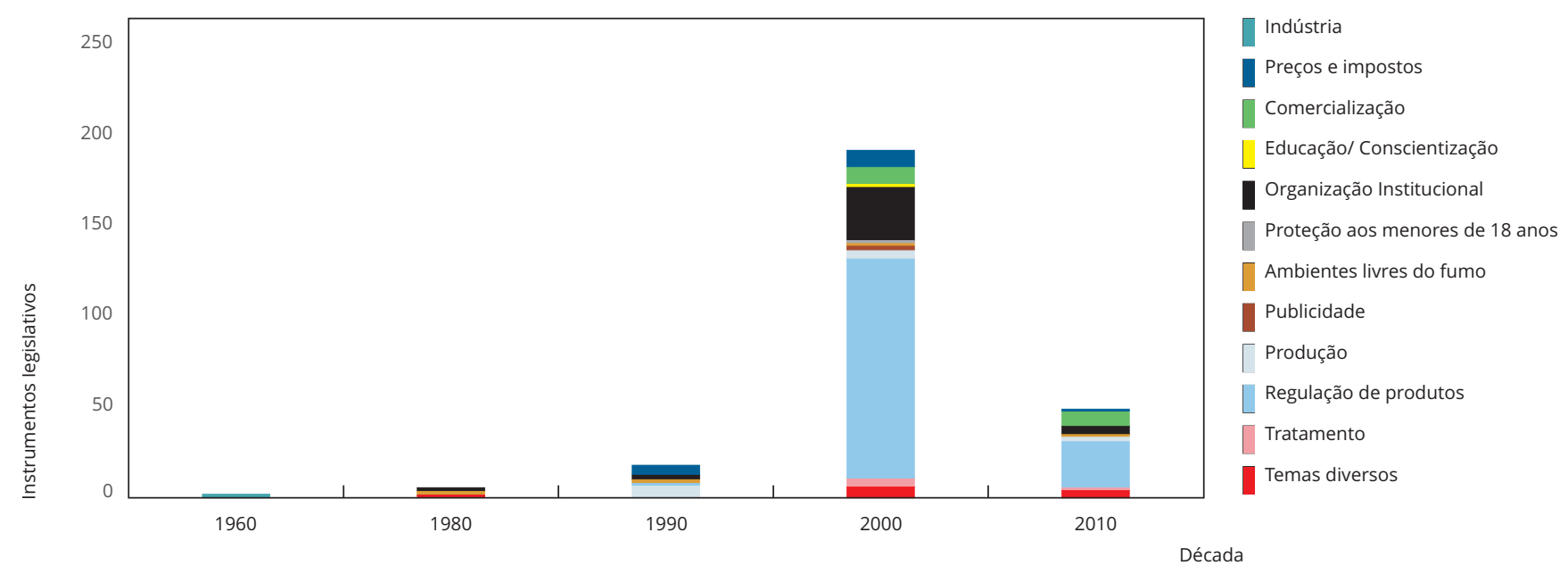

Fonte: elaborado pelos autores, a partir de diversas fontes: Saúde Legis (http://portal2.saude.gov.br/saudelegis/LEG_NORMA_PESQ_CONSULTA.CFM); Sistema de Informações do Congresso Nacional - Senado Federal (http://legis.senado.gov.br/sicon/); Portal da Legislação - Presidência da República (http://www4.planalto.gov.br/legislacao); Secretaria da Receita Federal (http://normas.receita.fazenda.gov.br/sijut2consulta/consulta.action) e Banco Central do Brasil (http://www.bcb.gov.br/Pre/CMN/resolucao_recente.asp).

Nota: (1) as normas quantificadas envolvem instruções normativas, portarias e resoluções, e correspondem aos resultados da busca de publicações contendo, pelo menos, um dos termos: cigarro, fumo, tabaco e tabagismo. Não necessariamente correspondem a medidas de controle do tabaco;

(2) a categoria "Temas diversos" refere-se às publicações que envolvem mais de uma das demais categorias.

veículos de comunicação, à restrição da publicidade dos produtos derivados do tabaco e à promoção de ambientes livres do fumo. A Constituição Federal de 1988 respaldou as restrições à propaganda e a inclusão de advertências sobre os malefícios do tabagismo. Ressalta-se também a Lei no 9.294/1996 10, que configurou a base legislativa para o controle do tabaco, ao proibir o fumo em recintos coletivos fechados (exceto nos "fumódromos"), restringir a propaganda dos produtos e estabelecer especificações sobre advertências relativas aos malefícios do tabagismo.

\section{- Negociações da CQCT-OMS e ratificação do tratado pelo Brasil (1999-2005)}

Entre o fim dos anos 1990 e meados dos anos 2000, intensificaram-se os debates sobre o controle do tabaco. A maior conscientização da sociedade sobre os malefícios do tabagismo favoreceu o aumento da sua rejeição social. As negociações internacionais visando à criação da CQCT-OMS, entre 1999 e 2003, e o processo de adesão ao tratado, entre 2003 e 2005, também conferiram destaque ao tema.

Até 2002, ressalta-se o papel do Ministério da Saúde, do INCA e de lideranças das sociedades médicas no controle do tabaco:

"Nos outros países as coisas se moviam por pressão da sociedade civil. Aqui não, aqui se movia porque tinha uma liderança dentro do governo, lideranças dentro do INCA e outros, sociedades médicas e tal" (SC 3).

A Agência Nacional de Vigilância Sanitária (Anvisa), criada em 1999, foi apontada pelos entrevistados como fundamental para o avanço da regulação de produtos. Assim como no INCA, a atuação de servidores de carreira colaborou para o fortalecimento institucional do controle do tabaco no país.

Ressalte-se ainda a participação do país nas negociações internacionais da CQCT-OMS, inclusive presidindo o Órgão Negociador Intergovernamental da Convenção. A Comissão Nacional para o Controle do Uso do Tabaco, constituída em 1999 para subsidiar o país nas negociações do tratado, configurou-se como a base da coordenação intersetorial das ações de controle do tabaco em âmbito nacional. 
Figura 3

Evolução da prevalência (\%) de tabagismo (1989-2013) e principais marcos institucionais da política de controle do tabaco (1986-2016) no Brasil.

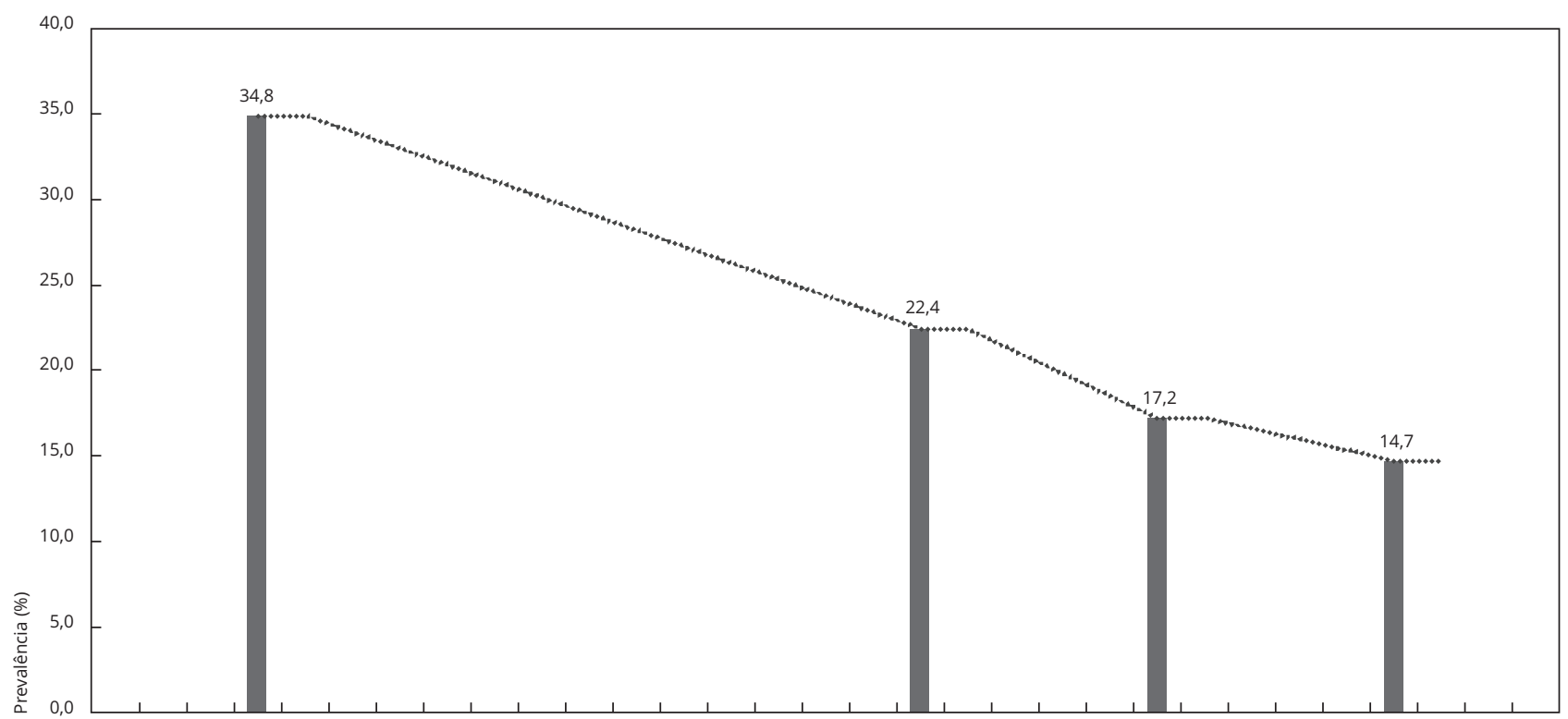

1986198719881989199019911992199319941995199619971998199920002001200220032004200520062007200820092010201120122013201420152016 Ano

\begin{tabular}{|c|c|}
\hline \multicolumn{2}{|r|}{ MARCOS INSTITUCIONAIS } \\
\hline 1986 & Conscientização \\
\hline 1988 & Advertências; ambiente livres do fumo; publicidade \\
\hline 1989 & Criação do PNCT \\
\hline 1990 & Advertências; ambiente livres do fumo; proteção aos menores de 18 anos; publicidade \\
\hline 1995 & Advertências; publicidade \\
\hline 1996 & Advertência; ambientes livres do fumo; publicidade \\
\hline 1997 & Comercialização \\
\hline 1998 & Comercialização \\
\hline 1999 & Advertências; regulação de produtos; Criação da Anvisa e da CNCT \\
\hline 2000 & Ambientes livres do fumo; publicidades \\
\hline 2001 & Advertências; produção; proteção aos menores de 18 anos; regulação de produtos \\
\hline 2002 & Ambientes livres do fumo; produção; regulação de produtos; tratamento \\
\hline 2003 & Advertências; comercialização; proteção aos menores de 18 anos; publicidades; Criação da CONIQT \\
\hline 2004 & Tratamento \\
\hline 2005 & Ratificação da CQCT-OMS \\
\hline 2006 & Promulgação da CQCT-OMS; adoção do termo PNCT \\
\hline 2007 & Comercialização; regulação de produtos; Criação da CIMICQ \\
\hline 2008 & Advertências; proteção aos menores de 18 anos \\
\hline 2009 & Regulação de produtos \\
\hline 2011 & Advertếncias; ambiente livres de fumo; comercialização; conscientização; preços e impostos; publicidades \\
\hline 2012 & Advertências; produção; regulação de produtos \\
\hline 2013 & Advertências; proteção aos menores de 18 anos; regulação de produtos; tratamento \\
\hline 2014 & Ambiente livre do fumo; publicidades \\
\hline 2016 & Conscientização; preços e impostos; produção; tratamento \\
\hline
\end{tabular}

Anvisa: Agência de Vigilância Sanitária; CNCT: Comissão Nacional para o Controle do Uso do Tabaco; CIMICQ: Comissão para promover a internalização da Convenção-Quadro para o Controle do Tabaco no âmbito do Sistema Único de Saúde; CONICQ: Comissão Nacional para Implementação da Convenção-Quadro para o Controle do Tabaco; CQCT-OMS: Convenção-Quadro sobre Controle do Uso do Tabaco da Organização Mundial da Saúde; PNCF: Programa Nacional de Combate ao Fumo.

Fonte: autores, adaptado da figura 2-2 de Figueiredo 58. Prevalência de fumantes - 1989 e 2003: Monteiro et al. 22; Prevalência de fumantes - 2008: Instituto Nacional de Câncer José de Alencar Gomes da Silva 34; Prevalência de fumantes - 2013: Instituto Brasileiro de Geografia e Estatística 59. Nota: (1) os temas citados estão relacionados aos marcos instituidores, legislativos e normativos da política brasileira de controle do tabaco; (2) a prevalência de fumantes refere-se ao consumo de tabaco fumado a partir dos principais inquéritos nacionais já realizados: Pesquisa Nacional sobre Saúde e Nutrição (PNSN) 1989, Pesquisa Mundial de Saúde 2003, Pesquisa Especial de Tabagismo (PETab) 2008 e Pesquisa Nacional de Saúde (PNS) 2013. 
Tabela 1

Principais marcos e estratégias da política brasileira de controle do tabaco entre 1986 e 2016.

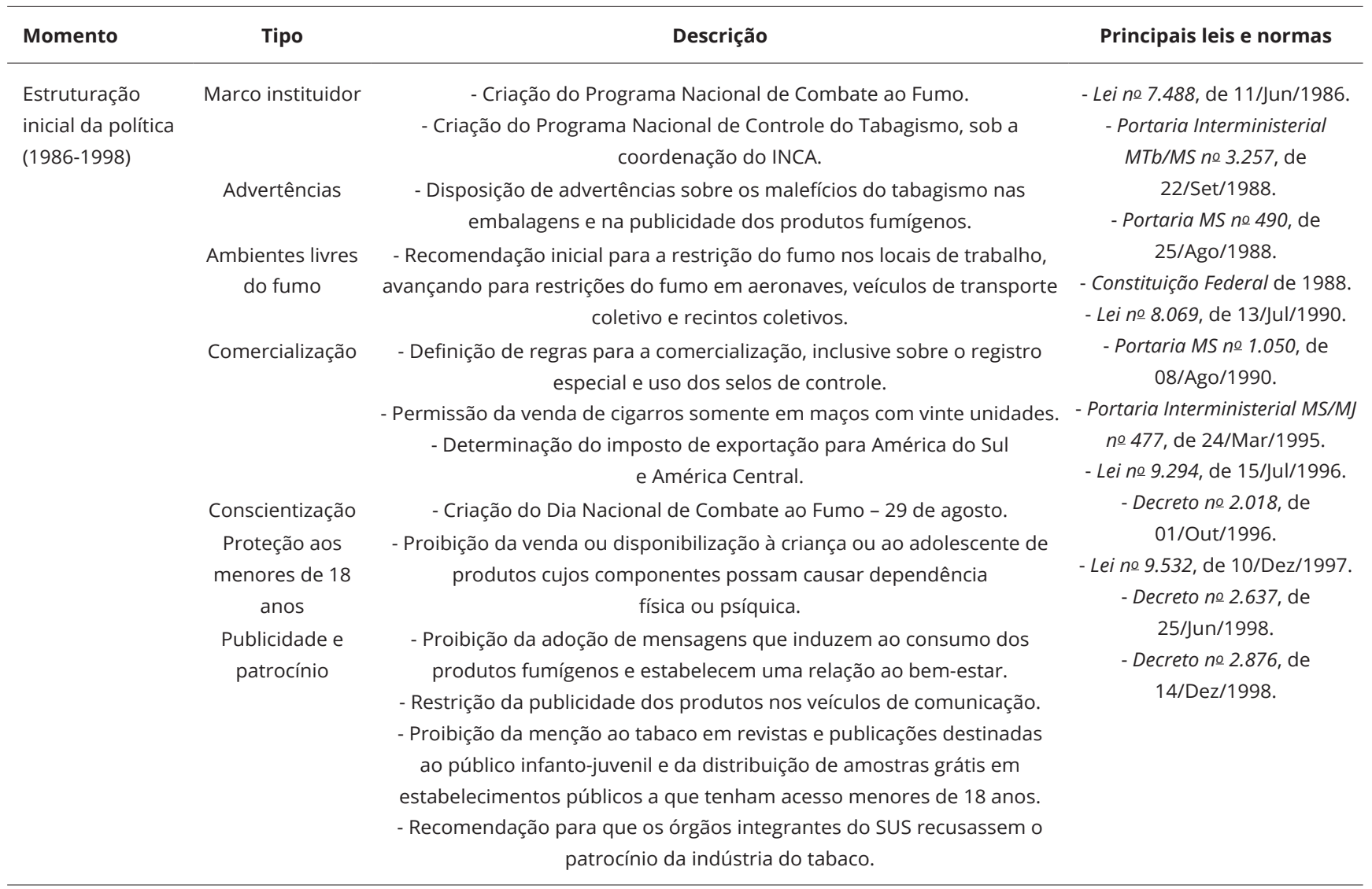

(continua)

A partir da criação da CQCT-OMS em 2003, a CONICQ passou a ser a responsável pela coordenação intersetorial da política brasileira de controle do tabaco. A Comissão, liderada pelo Ministério da Saúde e com o INCA como secretaria executiva, foi fundamental para conferir maior legitimidade às ações de controle do tabaco e mediar conflitos entre setores. Nesse período, profissionais de saúde, ativistas e associações médicas e acadêmicas passaram a se destacar na política, sob a liderança da Aliança de Controle do Tabagismo (ACT).

Apesar dos esforços dos ministérios da Saúde e das Relações Exteriores, observaram-se dificuldades na ratificação da CQCT-OMS pelo país. Debates em torno dos aspectos econômicos envolvendo a fumicultura foram frequentes. As associações relacionadas à cadeia produtiva do fumo, bem como ministérios da área econômica e alguns parlamentares, apresentaram resistências à ratificação do tratado, que só ocorreu em 2005.

Por fim, vale destacar a diversidade de leis e normas entre 1999 e 2005, como a Lei Federal no 10.167/2000 11, que restringiu a propaganda nos locais de venda, e a Portaria no 1.035/2004 do Ministério da Saúde 12, que ampliou o tratamento do tabagismo no SUS. Ressalta-se nesse período a significativa normatização sobre os produtos derivados do tabaco.

\section{- Implementação da CQCT-OMS no Brasil (2006-2016)}

A partir da ratificação da CQCT-OMS pelo Brasil em 2005 e da sua entrada em vigor em 2006, o termo Política Nacional de Controle do Tabaco (PNCT) passou a fazer referência ao conjunto de ações 
Tabela 1 (continuação)

\begin{tabular}{|c|c|c|c|}
\hline Momento & Tipo & Descrição & Principais leis e normas \\
\hline Negociações & Marco instituidor & - Criação da Comissão Nacional para o Controle & - Lei no 9.782, de 26/Jan/1999. \\
\hline da CQCT-OMS & & do Uso do Tabaco. & - Decreto $n$ o 3.070, de \\
\hline e ratificação do & & - Criação da Agência Nacional de Vigilância Sanitária. & 27/Mai/1999. \\
\hline tratado pelo & & - Criação da CONICQ. & - Portaria MS no 695, de \\
\hline Brasil (1999- & & - Ratificação da CQCT pelo Brasil. & 01/Jun/1999. \\
\hline \multirow[t]{42}{*}{ 2005) } & Advertências & - Inclusão do número do serviço Disque Pare de Fumar e de imagens nas & - Decreto no 3.136 , de \\
\hline & & advertências dos produtos fumígenos & 13/Ago/1999. \\
\hline & & e de sua publicidade. & - RDC Anvisa no 02, de \\
\hline & & - Determinação para a disposição de advertências em eventos esportivos & 04/Out/1999. \\
\hline & & internacionais sem sede fixa e na sua & - Lei no 10.167, de \\
\hline & & transmissão na televisão. & 27/Dez/2000. \\
\hline & & - Proibição do uso de invólucro que dificulte a visualização das imagens & - RDC Anvisa no 46, de \\
\hline & & das advertências nas embalagens & 28/Mar/2001. \\
\hline & & dos produtos fumígenos. & - RDC Anvisa no 104, de \\
\hline & Ambientes livres & - Proibição do fumo em aeronaves e demais veículos de transporte & 31/Mai/2001. \\
\hline & do fumo & coletivo. & - Medida Provisória no 2.134, \\
\hline & & - Recomendação às instituições de saúde e de ensino para implantarem & de $21 / J u n / 2001$ \\
\hline & & programas de Ambientes Livres do fumo. & - Portaria MTE no 20, de \\
\hline & Comercialização & - Proibição da comercialização de produtos fumígenos em & 13/Set/2001. \\
\hline & & estabelecimentos da Administração Pública. & - Resolução BC no 2.900, de \\
\hline & & - Proibição da venda de produtos derivados & 31/Out/2001. \\
\hline & & do tabaco na Internet. & - Resolução BC no 3.001, de \\
\hline & $\begin{array}{l}\text { Preços e } \\
\text { impostos }\end{array}$ & $\begin{array}{c}\text { - Determinação de que o IPI incidente sobre os cigarros passa a ser } \\
\text { calculado sob a forma de alíquota específica, de acordo com a classe fiscal } \\
\text { de enquadramento do produto. }\end{array}$ & $\begin{array}{l}\text { 24/Jul/2002. } \\
\text { - Portaria MS/MEC no } 1.498 \text {, } \\
\text { de 22/Ago/2002. }\end{array}$ \\
\hline & Produção & - Estabelecimento de critérios para a concessão de créditos do Pronaf aos & - Portaria MS no 1.575, de \\
\hline & & produtores de fumo em regime de parceria ou integração com indústrias & 29/Ago/2002. \\
\hline & & fumageiras. & - RDC Anvisa no 304, \\
\hline & & - Lançamento do Programa Nacional de Diversificação em Áreas & 07/Nov/2002. \\
\hline & & Cultivadas com Tabaco. & - RDC Anvisa no 15, de \\
\hline & Proteção aos & - Proibição do trabalho do menor de 18 anos no & 17/Jan/2003. \\
\hline & menores de 18 & setor produtivo do fumo. & - Lei no 10.702, de 14/Jul/2003. \\
\hline & anos & - Proibição da venda de produtos fumígenos a & - Decreto de 01/Ago/2003. \\
\hline & & menores de 18 anos. & - RDC Anvisa no 335, de \\
\hline & Publicidade & - Permissão da propaganda somente nos locais de venda. & 21/Nov/2003. \\
\hline & & - Proibição do patrocínio de eventos culturais e esportivos. & 31/Mai/2 \\
\hline & $\begin{array}{l}\text { Regulação de } \\
\text { produtos }\end{array}$ & - Registro de produtos fumígenos pela Anvisa. & - Portaria MS no 442, de \\
\hline & & substâncias dos cigarros. & 13/Ago/2004. \\
\hline & & $\begin{array}{c}\text { - Proibição da utilização de termos associados ao teor das substâncias na } \\
\text { embalagem ou material publicitário dos cigarros. }\end{array}$ & $\begin{array}{l}\text { - Resoluçao BL no } 3.299 \text {, de } \\
\text { 15/Jul/2005. }\end{array}$ \\
\hline & & - Proibição de alimentos com forma de apresentação semelhante a & - Decreto Legis/ativo no 1.012 \\
\hline & & produtos fumígenos e de embalagens de alimentos que simulem as & de $27 /$ Out/2005. \\
\hline & & embalagens de produtos fumígenos ou que utilizem nomes de marcas & \\
\hline & & desses produtos. & \\
\hline & Tratamento & - Criação de Centros de Referência em Abordagem & \\
\hline & & e Tratamento do Fumante. & \\
\hline & & - Ampliação do acesso ao tratamento do tabagismo no SUS, por meio do & \\
\hline & & Programa Nacional de Controle do Tabagismo. & \\
\hline & & - Aprovação do Protocolo Clínico e Diretrizes Terapêuticas da Dependência & \\
\hline & & à Nicotina. & \\
\hline
\end{tabular}

(continua) 
Tabela 1 (continuação)

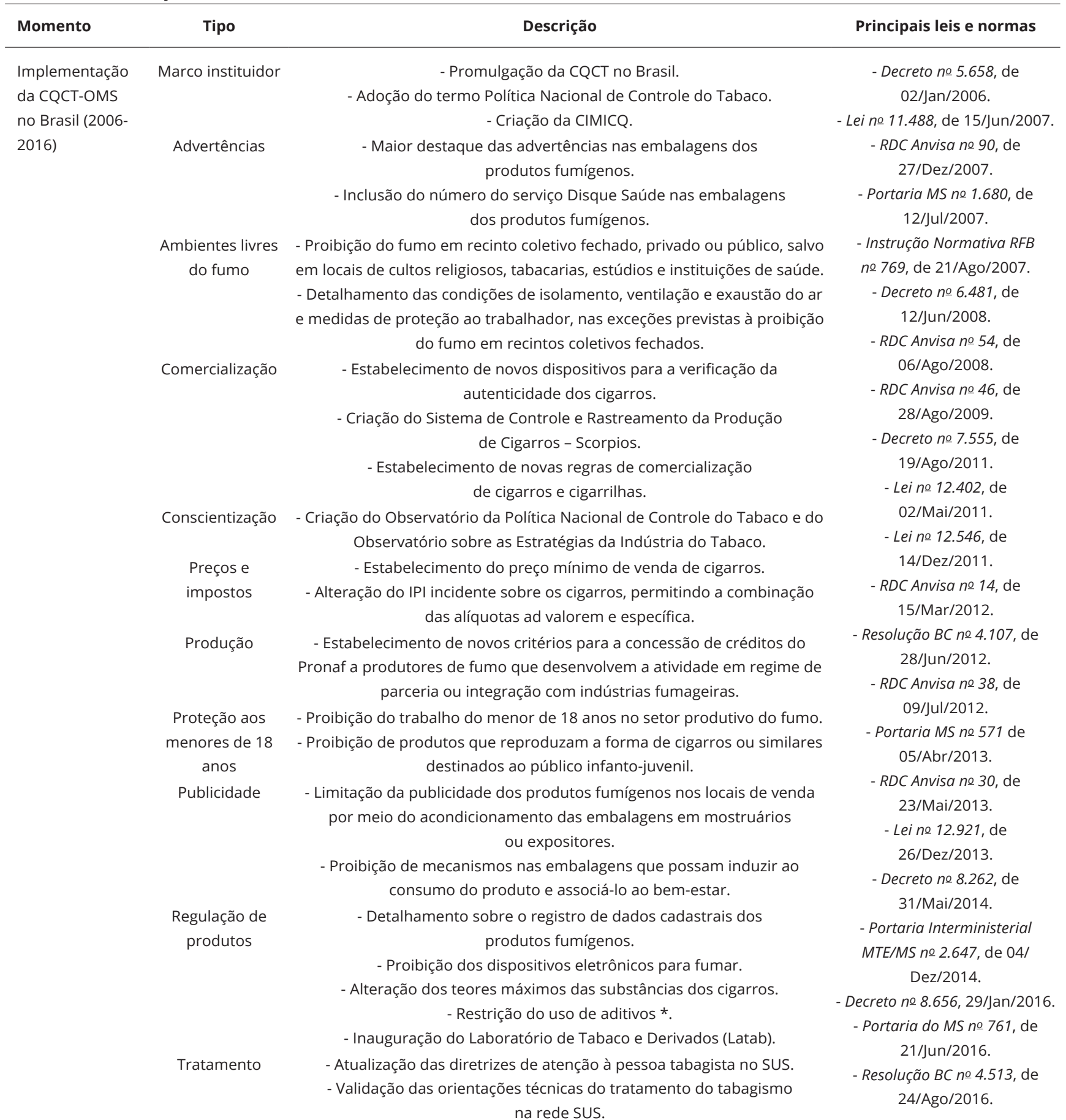

Anvisa: Agência de Vigilância Sanitária; BC: Banco Central; CIMICQ: Comissão para promover a internalização da Convenção-Quadro para o Controle do Tabaco no âmbito do Sistema Único de Saúde; CNCT: Comissão Nacional para o Controle do Uso do Tabaco; CQCT-OMS: Convenção-Quadro sobre Controle do Uso do Tabaco da Organização Mundial da Saúde; CONICQ: Comissão Nacional para Implementação da Convenção-Quadro para o Controle do Tabaco; INCA: Instituto Nacional de Câncer; IPI: Imposto sobre Produtos Industrializados; MJ: Ministério da Justiça; MS: Ministério da Saúde; MTb: Ministério do Trabalho; PNCF: Programa Nacional de Combate ao Fumo; Pronaf: Programa Nacional de Fortalecimento da Agricultura Familiar; RDC: Resolução da Diretoria Colegiada; RFB: Receita Federal do Brasil; SUS: Sistema Único de Saúde.

Fonte: elaboração dos autores.

Nota: (1) foram mencionados os principais acontecimentos relacionados a cada tema; (2) as advertências sobre os malefícios do tabagismo estão relacionadas à publicidade e à regulação dos produtos. No entanto, optou-se pela apresentação dos seus marcos separadamente, devido à relevância do tema.

* Em 2013, houve a suspensão da proibição de aditivos por uma Ação Direta de Inconstitucionalidade do Supremo Tribunal Federal. 
intersetoriais antitabagistas. A estruturação da política previamente à implementação da CQCT-OMS no país contribuiu para a sua continuidade e consolidação da rejeição social ao tabagismo no país.

A implementação da CQCT-OMS em todo o mundo favoreceu o fortalecimento das ações de controle do tabaco no Brasil. Destaquem-se, em 2012, a adoção do Protocolo para Eliminar o Comércio Ilícito de Produtos de Tabaco pela quinta sessão da Conferência das Partes (COP5) 13 e, em 2013, a inclusão da redução da prevalência do tabagismo como uma das metas globais para a prevenção e controle das doenças crônicas não transmissíveis 14. As comemorações dos dez anos da CQCT-OMS, em 2015, estimularam o debate sobre os desafios a serem superados.

Nesse período, o tratado internacional passou a se configurar como a principal referência para a consolidação da política brasileira.

“...o embasamento das medidas do tratado, como justificativa para implementar ações duras, é fundamental. Então, também foi um movimento onde o Brasil ficou um bom período negociando, fazendo o seu trabalho interno. Quando o tratado saiu, o Brasil começou a utilizar o tratado como base da sua política nacional" (Sec. CQCT-OMS).

Além do Ministério da Saúde, outros atores também participaram ou buscaram influenciar a formulação e a implementação da política nacional no período: outros ministérios federais, o Legislativo, organizações não governamentais e representantes de segmentos econômicos da cadeia produtiva do tabaco.

Visando à otimização da implementação da CQCT-OMS nos setores abrangidos pela CONICQ, ressalta-se o estímulo à criação de comissões destinadas ao controle do tabaco nos ministérios envolvidos. Essa proposta foi adotada somente pelo Ministério da Saúde em 2007, mas enfrentou conflitos internos.

Destaquem-se os conflitos envolvendo o direcionamento de poder no Ministério da Saúde. Apesar de o INCA integrar a estrutura organizacional do Ministério como um órgão da Secretaria de Atenção à Saúde desde o início dos anos 1990, a sua capacidade de atuação no controle do tabaco variou ao longo dos anos. Relatos destacaram a autonomia técnica e administrativa do INCA até 2010, sob menor influência do contexto político que afetava o Ministério da Saúde, em Brasília. A partir de 2011, deslocaram-se competências do INCA para a sede do Ministério, sobretudo em relação à coordenação nacional das ações de tratamento de fumantes. A reestruturação organizacional de 2013 reforçou esse movimento, ao atribuir à Coordenação-Geral de Atenção às Pessoas com Doenças Crônicas a responsabilidade pela elaboração e avaliação das políticas de prevenção e controle do câncer. No entanto, alguns entrevistados argumentaram que o INCA manteve protagonismo na coordenação da PNCT.

Por fim, entre 2006 e 2016, ressaltam-se a Lei Federal no 12.546/2011 15 e o Decreto no 8.262/2014 16, que proibiram os fumódromos e ampliaram as restrições da propaganda dos produtos fumígenos e o destaque das advertências nas embalagens dos produtos. Também vale destacar os desdobramentos envolvendo a proibição de aditivos e os avanços relacionados aos preços e impostos de cigarros.

\section{Avanços, limites e desafios da política brasileira de controle do tabaco}

A Tabela 2 apresenta uma síntese dos avanços, limites e desafios das principais medidas implantadas no país. Entre as medidas que visam à redução da demanda de tabaco, destaca-se o aumento dos preços e impostos de cigarros, cuja eficiência para o desestímulo ao tabagismo e geração de receitas colaborou para o interesse dos Ministérios da Saúde e da Fazenda. A participação da Secretaria da Receita Federal na CONICQ foi determinante para a progressão da tributação de cigarros no país. No entanto, esse processo sofreu resistência da indústria do fumo, sob argumento da relação entre aumento dos preços e comércio ilícito. Constatou-se a expectativa entre os membros da CONICQ em torno da criação de um Fundo de Reparação Civil e da Contribuição de Intervenção no Domínio Econômico incidente sobre o tabaco (CIDE-Tabaco), visando ao custeio de despesas com os danos à saúde decorrentes do tabagismo. No entanto, barreiras técnicas, econômicas e políticas têm dificultado a criação desses mecanismos.

Considerando a regulação de produtos, ressalta-se o embate sobre os aditivos dos produtos derivados do tabaco. Sob o entendimento de que a proibição dos aditivos resultaria em perdas econômicas, o setor produtivo do fumo tem rejeitado as iniciativas da Anvisa de regulação da matéria e atuado junto ao Executivo e Legislativo para evitá-las. Os conflitos se intensificaram com a publicação 
Tabela 2

Avanços, limites e desafios relacionados às principais medidas de controle do tabaco. Brasil, 1986-2016.

\begin{tabular}{|c|c|c|c|}
\hline $\begin{array}{l}\text { Medidas/Artigos } \\
\text { CQCT-OMS }\end{array}$ & Avanços & Limites & Desafios \\
\hline $\begin{array}{l}\text { Preços e } \\
\text { impostos/ } \\
\text { Artigo 6o }\end{array}$ & $\begin{array}{l}\text { - Reajustes periódicos do IPI, ICMS, PIS/ } \\
\text { Pasep e Cofins incidentes sobre cigarros. } \\
\text { - Criação do regime especial do IPI como } \\
\text { alternativa ao regime geral do IPI. } \\
\text { - Estabelecimento de preço mínimo de } \\
\text { venda de cigarros, com reajustes anuais. } \\
\text { - A partir de } 2016 \text { : carga tributária de } \\
\text { maço de cigarros vendido a } \mathrm{R} \$ 5,00 \\
\text { corresponde a } 81 \%(1,2) \text {. }\end{array}$ & $\begin{array}{l}\text { - Resistência do setor produtivo do fumo. } \\
\text { - Foco da política tributária nos cigarros. } \\
\text { - Frágil combate ao comércio ilícito. } \\
\text { - Dificuldades de direcionamento } \\
\text { dos recursos arrecadados para o } \\
\text { financiamento de ações da PNCT. }\end{array}$ & $\begin{array}{c}\text { - Manutenção de reajustes anuais dos } \\
\text { preços e impostos incidentes sobre } \\
\text { cigarros. } \\
\text { - Aumento da tributação dos diversos } \\
\text { produtos fumígenos. } \\
\text { - Intensificação do combate ao mercado } \\
\text { ilegal de cigarros. } \\
\text { - Destinação da arrecadação para a } \\
\text { PNCT. }\end{array}$ \\
\hline $\begin{array}{l}\text { Promoção de } \\
\text { ambientes livres } \\
\text { do fumo/Artigo 8o }\end{array}$ & $\begin{array}{l}\text { - Proibição do fumo em ambientes } \\
\text { coletivos fechados, salvo em locais de } \\
\text { culto religioso, tabacarias, estúdios e } \\
\text { instituições de saúde. } \\
\text { - Formulação de legislações estaduais e } \\
\text { municipais de promoção de ambientes } \\
\text { livres do fumo. } \\
\text { - Fiscalização dos estabelecimentos pela } \\
\text { vigilância sanitária, nas três esferas } \\
\text { de governo. }\end{array}$ & $\begin{array}{c}\text { - Resistência do setor produtivo do fumo } \\
\text { e de grupos específicos do } \\
\text { setor comercial. } \\
\text { - Embates envolvendo a liberdade } \\
\text { individual e a interpretação } \\
\text { das legislações. } \\
\text { - Fragilidades de recursos físicos e } \\
\text { humanos da vigilância sanitária nos } \\
\text { estados e municípios. } \\
\text { - Manutenção de exceções do fumo em } \\
\text { recintos coletivos fechados. }\end{array}$ & $\begin{array}{l}\text { - Proibição total do fumo em recintos } \\
\text { coletivos fechados. } \\
\text { - Redução do fumo passivo em recintos } \\
\text { particulares, como nos transportes } \\
\text { coletivos individuais e domicílios. } \\
\text { - Fortalecimento dos recursos físicos } \\
\text { e humanos da vigilância sanitária nos } \\
\text { estados e municípios. } \\
\text { - Harmonização da legislação das três } \\
\text { esferas de governos destinadas à } \\
\text { promoção de ambientes livres do fumo. }\end{array}$ \\
\hline $\begin{array}{l}\text { Regulação de } \\
\text { produtos/Artigos }\end{array}$ & $\begin{array}{c}\text { - Atuação da Anvisa na regulação } \\
\text { de produtos. }\end{array}$ & $\begin{array}{l}\text { - Resistência do setor produtivo do fumo. } \\
\text { - Judicialização pela indústria do fumo da }\end{array}$ & $\begin{array}{c}\text { - Adoção de embalagens padronizadas } \\
\text { de cigarros. }\end{array}$ \\
\hline $9 ㅇ, 10$ 으 e 11 으 & $\begin{array}{l}\text { - Inclusão de advertências sobre os } \\
\text { malefícios do tabagismo (mensagens e } \\
\text { imagens) nas embalagens dos produtos } \\
\text { e do número do serviço Disque Saúde. } \\
\text { - Limitação dos teores máximos das } \\
\text { substâncias dos cigarros. } \\
\text { - Proibição da utilização de termos } \\
\text { associados ao teor das substâncias na } \\
\text { denominação dos cigarros. } \\
\text { - Proibição dos dispositivos eletrônicos } \\
\text { para fumar. } \\
\text { - Criação do Laboratório de Tabaco e } \\
\text { Derivados (Latab). }\end{array}$ & $\begin{array}{l}\text { atuação da Anvisa sobre a regulação de } \\
\text { produtos fumígenos. } \\
\text { - Expansão dos novos } \\
\text { produtos fumígenos. }\end{array}$ & $\begin{array}{c}\text { - Elaboração de advertências que } \\
\text { contemplem a diversidade de grupos } \\
\text { correspondentes ao público fumante. } \\
\text { - Legitimação da Anvisa na regulação de } \\
\text { produtos fumígenos a partir de decisões } \\
\text { favoráveis no Judiciário e ampliação do } \\
\text { apoio popular às suas ações. } \\
\text { - Aprimoramento da capacidade } \\
\text { de regulação dos novos } \\
\text { produtos fumígenos. }\end{array}$ \\
\hline
\end{tabular}

(continua)

da $R D C$ no 14/2012 da Anvisa, que previu a restrição de aditivos nos produtos derivados do tabaco. A RDC foi contestada judicialmente pela indústria do fumo e, a partir de uma decisão monocrática do Supremo Tribunal Federal (STF) ${ }^{17}$, teve os seus artigos referentes aos aditivos suspensos. As atas das reuniões da CONICQ evidenciam iniciativas da Advocacia Geral da União (AGU), do Ministério da Saúde (INCA e Anvisa) e da sociedade civil (ACT) buscando reverter os efeitos das ações movidas pela indústria do fumo.

Entre as medidas relacionadas à redução da oferta de tabaco, a diversificação de culturas representou o principal elemento de tensão da PNCT, marcado por conflitos envolvendo os setores ligados à cadeia produtiva do tabaco e os setores sociais defensores da política. Um primeiro ponto refere-se ao embate entre as vantagens e as desvantagens da fumicultura para o agricultor familiar. Entre os setores ligados à cadeia produtiva do tabaco, observou-se a valorização de aspectos econômicos con- 
Tabela 2 (continuação)

\begin{tabular}{|c|c|c|c|}
\hline $\begin{array}{l}\text { Medidas/Artigos } \\
\text { CQCT-OMS }\end{array}$ & Avanços & Limites & Desafios \\
\hline $\begin{array}{l}\text { Educação e } \\
\text { conscientização } \\
\text { do público/ } \\
\text { Artigo 12o }\end{array}$ & $\begin{array}{l}\text { - Realização de campanhas anuais } \\
\text { de conscientização do público sobre } \\
\text { os malefícios do tabagismo nos dias } \\
\text { comemorativos: Dia Nacional de } \\
\text { Combate ao Fumo (29 de agosto) e Dia } \\
\text { Mundial sem Tabaco (31 de maio). } \\
\text { - Desenvolvimento de ações educativas } \\
\text { em escolas, unidades de saúde e } \\
\text { ambientes de trabalho. Destaque para } \\
\text { o Programa Saber Saúde, integrante do } \\
\text { Programa Saúde na Escola, que alcançou } \\
\text { 2.389.126 alunos de 14.280 escolas em } \\
\text { 1.212 municípios (3). } \\
\text { - Criação de observatórios para a } \\
\text { divulgação de informações relacionadas } \\
\text { ao controle do tabaco no Brasil: } \\
\text { Observatório da Política Nacional de } \\
\text { Controle do Tabaco e o Observatório } \\
\text { sobre as Estratégias da Indústria do } \\
\text { Tabaco no Brasil. }\end{array}$ & $\begin{array}{l}\text { - Foco nas campanhas. } \\
\text { - Carência de recursos e articulação } \\
\text { intersetorial para a expansão de ações } \\
\text { educativas contínuas. } \\
\text { - Diversidade do público (faixa etária, } \\
\text { perfil econômico, gênero, cultura e estilo } \\
\text { de vida). } \\
\text { - Dificuldades para a divulgação de } \\
\text { informações sobre os diversos temas } \\
\text { relacionados ao controle do tabaco. } \\
\text { - Renovação permanente das estratégias } \\
\text { da indústria do fumo. } \\
\text { - Desgastes em resposta à } \\
\text { desinformação gerada pela indústria do } \\
\text { fumo. }\end{array}$ & $\begin{array}{l}\text { - Avanços em ações intersetoriais. } \\
\text { - Fortalecimento e expansão do } \\
\text { Programa Saber Saúde. } \\
\text { - Elaboração de estratégias de } \\
\text { comunicação que considerem as } \\
\text { especificidades dos diversos grupos. } \\
\text { - Ampliação de ações educativas } \\
\text { que contemplem novos produtos de } \\
\text { fumígenos, estratégias da indústria, } \\
\text { comércio ilícito, diversificação das } \\
\text { áreas de cultivo de tabaco e danos da } \\
\text { fumicultura aos agricultores e ao meio } \\
\text { ambiente. } \\
\text { - Ampliação da capacitação para a } \\
\text { realização de ações educativas. } \\
\text { - Criação de mecanismos de avaliação e } \\
\text { monitoramento das ações adotadas. }\end{array}$ \\
\hline $\begin{array}{l}\text { Restrição à } \\
\text { publicidade e } \\
\text { propaganda/ } \\
\text { Artigo 13o }\end{array}$ & $\begin{array}{l}\text { - Proibição de mensagens que induzam } \\
\text { ao consumo de produtos fumígenos e a } \\
\text { sua relação com bem-estar ou saúde. } \\
\text { - Proibição da distribuição de amostras } \\
\text { grátis de produtos de tabaco em } \\
\text { diversos estabelecimentos. } \\
\text { - Proibição do patrocínio de eventos } \\
\text { culturais e esportivos pela indústria do } \\
\text { tabaco. } \\
\text { - Limitação da propaganda somente } \\
\text { por meio do acondicionamento dos } \\
\text { produtos fumígenos nos mostruários ou } \\
\text { expositores nos locais de venda. }\end{array}$ & $\begin{array}{l}\text { - Resistência do setor produtivo do fumo. } \\
\text { - Renovação das estratégias de } \\
\text { publicidade da indústria. } \\
\text { - Dificuldades para o controle da } \\
\text { publicidade e patrocínio na Internet. }\end{array}$ & $\begin{array}{l}\text { - Aprovação da proibição total do } \\
\text { patrocínio e da propaganda dos produtos } \\
\text { derivados do tabaco. } \\
\text { - Ampliação da fiscalização do patrocínio } \\
\text { e da publicidade, com a aplicação das } \\
\text { penalidades. } \\
\text { - Restrição da publicidade de novos } \\
\text { produtos fumígenos. }\end{array}$ \\
\hline
\end{tabular}

(continua)

feridos ao agricultor, como a maior rentabilidade em relação ao cultivo de outras culturas, a relativa estabilidade da demanda pelo tabaco e o suporte conferido pela indústria na produção integrada. Já os setores sociais enfatizaram os danos à saúde dos agricultores, o regime intenso e insalubre de trabalho, a insatisfação com a atividade e o endividamento dos agricultores com a indústria.

Um segundo conflito reporta-se à divergência sobre a diversificação em áreas de cultivo de tabaco, ponto evidenciado pela Declaração de Interpretação de Dispositivos da CQCT-OMS 18, assinada dias antes da ratificação do tratado pelo Brasil, por meio dos ministros da Agricultura, Pecuária e Abastecimento; do Desenvolvimento Agrário; da Fazenda; da Saúde; das Relações Exteriores; e da Casa Civil. Dentre outros aspectos, tal documento expressa que a produção do fumo não seria proibida e que não haveria restrição a políticas de apoio aos agricultores que, na época, se dedicavam à fumicultura. No entanto, essa pactuação tornou-se conflituosa. Relatos de membros de setores sociais enfatizaram que a progressiva queda da prevalência mundial de fumantes justificaria a necessidade de avanços na diversificação. Já na perspectiva de representantes de setores ligados à cadeia produtiva do fumo, a diversificação implicaria a agregação de outras culturas, preservando a fumicultura enquanto houvesse demanda pelo tabaco. Ressalta-se o conflito gerado em torno do documento preparatório 
Tabela 2 (continuação)

$\begin{array}{ll}\text { Medidas/Artigos } & \text { Avanços } \\ \text { CQCT-OMS } & \text { Limites }\end{array}$

Tratamento de fumantes/ Artigo 14응
Combate ao comércio ilícito/ Artigo 15o das unidades básicas de saúde.

- Oferta da abordagem breve por meio do Disque Saúde.

- Em 2013, 604 municípios e 1.308 unidades ofereceram atendimento. 154.207 fumantes foram atendidos e 71.327 pararam de fumar. A taxa de abandono correspondeu a $28 \%$, a de cessação a 53\% e a de uso da medicação a $77 \%$ (4).
- Oferta do tratamento do tabagismo na
rede do SUS, principalmente por meio

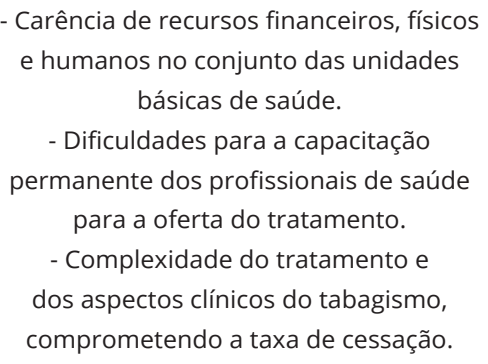

Carência de recursos financeiros, físicos e humanos no conjunto das unidades básicas de saúde.

- Dificuldades para a capacitação permanente dos profissionais de saúde para a oferta do tratamento.

- Complexidade do tratamento e dos aspectos clínicos do tabagismo, comprometendo a taxa de cessação.

- Consolidação da oferta de tratamento nas unidades básicas de saúde, com investimento, e estruturação e expansão da oferta na atenção secundária e terciária à saúde.

- Oferta de tratamento em locais variados, como ambientes de trabalho, de lazer e de ensino.

- Oferta de tratamento de acordo com o perfil de grupos específicos (gestantes, mulheres, jovens etc.).

- Ampliação da capacitação para o tratamento de fumantes, incluindo profissionais não médicos de nível superior e médio.

- Incorporação do tratamento do tabagismo no currículo acadêmico dos profissionais de saúde.

- Aumento da taxa de cessação.

- Aprimoramento do monitoramento dos indicadores de tratamento.

- Extensão territorial do país,

- Ratificação e implementação do

comprometendo o combate ao mercado Protocolo para Eliminar o Comércio llícito ilegal, principalmente nas fronteiras. de Produtos de Tabaco.

- Frágil articulação intersetorial para o - Elaboração de estudos sobre mercado combate ao mercado ilegal.

- Dificuldades na elaboração e Federal e Policia Federal no combate ao contrabando e à falsificação de cigarros, cumprimento da legislação sobre o tema, com destaque para o Sistema de Controle e Rastreamento da Produção de Cigarros (Scorpios).

- Em 2016, o valor correspondente ao montante de cigarros destruídos, a partir da apreensão por infração fiscal, alcançou R\$581 milhões (1). ilegal no Brasil.

- Fortalecimento da legislação relacionada ao comércio ilícito.

- Fortalecimento do monitoramento do comércio dos produtos de tabaco nas regiões fronteiriças, sobretudo no Paraguai.

- Harmonização da legislação brasileira com a dos países vizinhos, relacionada ao combate ao comércio ilícito e aos preços e impostos de produtos de tabaco.

(continua)

para a COP5 do grupo de trabalho internacional sobre alternativas sustentáveis para a fumicultura 19 . O documento, que dentre outros pontos recomendava a redução de áreas plantadas do fumo, gerou insatisfação desse setor produtivo. Após intensos debates, decidiu-se que o posicionamento da delegação brasileira deveria ser contrário a essa proposta.

Por fim, um terceiro conflito envolvendo a fumicultura refere-se às limitações governamentais para garantir avanços na diversificação de culturas. O Programa Nacional de Diversificação em Áreas Cultivadas com Tabaco 20, lançado em 2005, tem financiado projetos de pesquisa, capacitação e assistência técnica e extensão rural para a diversificação produtiva. Apesar de o Programa ter sido pactuado com outros ministérios por meio da Declaração de Interpretação de Dispositivos da CQCT-OMS 18, entrevistados apontaram que apenas o Ministério do Desenvolvimento Agrário e Ministério da Saúde têm empenhado esforços significativos para a sua implementação. O déficit de recursos humanos e financeiros e as divergências sobre o tema entre a CONICQ e a Câmara Setorial 
Tabela 2 (continuação)

$\begin{array}{ll}\text { Medidas/Artigos } & \text { Avanços } \\ \text { CQCT-OMS } & \end{array}$

Diversificação de

culturas/

Artigo 17으

Pesquisa e

vigilância/

Artigo 20응
- Estabelecimento de critérios para a concessão de crédito do Programa

Nacional de Fortalecimento da Agricultura Familiar aos fumicultores em regime de parceria ou integração com a indústria do fumo. Para a concessão do benefício, no ano agrícola 2016/2017, é previsto que a receita bruta gerada por outras atividades que não a produção de fumo seja de, no mínimo, 20\%. Para o ano agrícola 2020/2021, a exigência mínima passa a ser de $50 \%$.

- Implementação do Programa de Diversificação em Áreas Cultivadas com Tabaco, com a oferta de projetos de extensão rural, formação e pesquisa.

- Entre 2011 e 2016, foi previsto o investimento de mais de $\mathrm{R} \$ 60$ milhões em ações de assistência técnica e extensão rural (Ater) para os principais municípios produtores de tabaco, envolvendo mais de 20 mil famílias (5). - Constituição do INCA como "Centro Colaborador da OMS para o Controle do Tabaco".

- Realização periódica de pesquisas envolvendo o monitoramento de indicadores sobre o tabagismo. - Lançamento do “Plano de Ações Estratégicas para o Enfrentamento das Doenças Crônicas não Transmissíveis no Brasil, 2011-2022", incluindo ações de vigilância, pesquisa e promoção da saúde relacionadas ao tabagismo.
- Forte resistência do setor produtivo.

- Relevância da fumicultura nas

economias locais, sobretudo na Região Sul do país.

- Escassez de recursos humanos e físicos da Secretaria de Agricultura Familiar do MDA, responsável pela coordenação das ações de diversificação.

- Frágil articulação intersetorial para a promoção de políticas públicas para a diversificação.

- Especificidades da fumicultura: vantagem econômica em relação

a outras culturas em pequenas

propriedades e ciclo ininterrupto do cultivo do fumo.

- Carência de estudos que apontem a viabilidade econômica de culturas alternativas.

\section{- Ampliação do número de beneficiados com políticas para a diversificação. \\ - Articulação com programas}

agrários e outros setores, visando ao

desenvolvimento sustentável econômico e social no território.

- Ampliação de políticas de acesso à terra para os pequenos agricultores.

- Maior investimento na capacitação profissional e educação das famílias para a promoção da diversificação e autonomia e na capacitação de profissionais de saúde para a assistência aos agricultores familiares.

- Realização permanente de pesquisas que subsidiem as ações de diversificação.

- Fortalecimento do monitoramento das ações de diversificação.
- Escassez de pesquisas que contemplem - Consolidação da realização periódica de o público diversificado de fumantes e outras dimensões além do perfil de fumantes e de morbimortalidade. - Carência de parcerias intersetoriais para pesquisas.
- Dinâmica de estratégias da indústria do fumo, levando à necessidade de novos indicadores.
- Escassez de financiamento de pesquisas nas esferas subnacionais.
pesquisas nacionais que abordam o tabagismo.
- Aperfeiçoamento dos instrumentos dos inquéritos existentes, visando à possibilidade de comparação dos dados com os de outros países.
- Ampliação de pesquisas sobre as variadas temáticas relacionadas ao tabaco, abrangendo regulação de produtos, comercialização, indústria do
fumo, diversificação de culturas, entre outros.
- Firmação de parcerias e grupos de pesquisa para a realização de estudos.
- Definição permanente de metas e análise dos fatores condicionantes para o alcance daquelas.

\footnotetext{
Anvisa: Agência de Vigilância Sanitária; Cofins: Contribuição para o Financiamento da Seguridade Social; CQCT-OMS: Conveção-Quadro sobre Controle do Uso do Tabaco da Organização Mundial da Saúde; ICMS: imposto estadual sobre operações relativas à circulação de mercadorias e sobre prestações de serviços de transporte interestadual e intermunicipal e de comunicação; INCA: Instituto Nacional de Câncer; IPI: Imposto sobre Produtos Industrializados; MDA: Ministério do Desenvolvimento Agrário; PIS/Pasep: Programas de Integração Social e de Formação do Patrimônio do Servidor Público; PNCT: Política Nacional de Controle do Tabaco.

Fonte: elaboração dos autores, a partir de diversas fontes: (1) Secretaria da Receita Federal do Brasil. Regimes e Controles Especiais. http://idg.receita. fazenda.gov.br/orientacao/tributaria/regimes-e-controles-especiais/registros-e-controles-especiais (acessado em 06/Jan/2017); (2) Observatório da Política Nacional de Controle do Tabaco. http://www2.inca.gov.br/wps/wcm/connect/observatorio_controle_tabaco/site/status_politica/educacao_ concientizacao (acessado em 06/Jan/2017); (3) Instituto Nacional de Câncer José Alencar Gomes da Silva 2; (4) Instituto Nacional de Câncer José Gomes da Silva 60; (5) Instituto Nacional de Câncer José Alencar Gomes da Silva 49.
} 
da Cadeia Produtiva do Fumo do MAPA 21 também foram destacados como fatores que têm prejudicado a diversificação.

Entre as medidas para redução da oferta de tabaco, foram identificadas fragilidades no combate ao comércio ilícito. Apesar da atuação da Receita Federal e Polícia Federal, o Brasil ainda apresenta limitações na contenção do mercado ilegal de cigarros. A ratificação e a implementação do Protocolo para Eliminar o Comércio Ilícito de Produtos e Tabaco configuram-se como desafios para a PNCT. As atas das reuniões da CONICQ evidenciam esforços para avanços nessa pauta, empenhados principalmente por membros dos ministérios da Saúde (Assessoria de Assuntos Internacionais de Saúde, Anvisa e INCA), Fazenda (Receita Federal), Justiça (Polícia Federal) e Relações Exteriores.

Por fim, ressaltam-se os desafios envolvendo a indústria do fumo e a sustentabilidade da política. Constatou-se que a indústria é considerada pelos setores sociais a maior ameaça para o controle do tabaco no Brasil. Entrevistados destacaram o lobby da indústria no Legislativo, no Judiciário e no próprio setor saúde, envolvendo o financiamento de campanhas políticas e o patrocínio de eventos. As iniciativas de marketing e o investimento em novos produtos foram apontados como estratégias da indústria a serem contidas.

Em relação à sustentabilidade da PNCT, entrevistados sugeriram que os avanços alcançados no país nas últimas décadas podem levar à perda de prioridade política e de financiamento das ações de controle do tabaco no país. Nessa perspectiva, no âmbito nacional, outros temas relacionados à saúde pública passariam a ser prioritários, e, no plano internacional, países com políticas de controle do tabaco mais frágeis seriam priorizados pelas agências internacionais. A manutenção do controle do tabaco na agenda do setor saúde foi apontada como fundamental para a sustentabilidade da PNCT e para avanços na implementação intersetorial da CQCT-OMS.

\section{Discussão}

Diversos estudos atribuem a redução da prevalência de fumantes a partir dos anos 1980 principalmente às ações que visam ao desestímulo à iniciação ao fumo, como a conscientização da população, o aumento de preços e impostos de cigarros, a promoção de ambientes livres do fumo, a adoção de advertências sobre os malefícios do tabagismo e as restrições da publicidade, promoção e patrocínio do tabaco 22,23,24,25. Levy et al. 26, em análise das medidas entre 1989 e 2010, demonstraram que o principal fator responsável pela redução da prevalência do tabagismo foi o aumento de preços e impostos de cigarros 27.

Ressalta-se o papel decisivo da articulação entre lideranças do controle do tabaco, envolvendo servidores do INCA e representantes de organizações médicas, para o desenvolvimento da política ao longo dos anos 1990. A descentralização político-administrativa, carro-chefe no campo da política de saúde naquele período 28 , favoreceu o fortalecimento das ações de controle do tabagismo nos estados e municípios.

Wipfli et al. 29 consideram essencial a articulação entre evidências, infraestrutura e uma rede com expertise e liderança para a consolidação da capacidade nacional para o controle do tabaco. Pode-se considerar que o Brasil apresentou a estruturação inicial desses componentes previamente à criação da CQCT-OMS, em 2003. Isso favoreceu a continuidade e a consolidação da política, apesar do relativo enfraquecimento do controle do tabaco na agenda governamental em momentos específicos.

Ressaltam-se alguns fatores fundamentais que conferiram institucionalidade ao controle do tabaco no país. Um primeiro fator relaciona-se ao prestígio do Brasil no cenário internacional. A experiência brasileira com o controle do tabaco nas décadas de 1980 e 1990 contribuiu para que o país obtivesse reconhecimento internacional 30. O sucesso nas negociações da CQCT-OMS, além de alçar o Brasil à vanguarda mundial na saúde pública global 31, foi decisivo para o compromisso do país com a implementação da CQCT-OMS. A liderança do Brasil no cenário internacional foi mantida ao longo dos anos, destacando-se a nomeação de uma brasileira como chefe do Secretariado da CQCT-OMS em 2014.

Um segundo fator refere-se à sólida estruturação da política brasileira de controle do tabaco iniciada nos anos 1980. O PNCF inseriu-se no SUS por meio de uma política multissetorial pioneira para o controle de fatores de risco ${ }^{32}$. A sua abordagem antecipava pontos que viriam a ser recomendados 
pela CQCT-OMS. A partir de 2003, a CONICQ permitiu fortalecer as relações entre os setores que demonstram compromisso com a implementação da CQCT-OMS no país 33 .

O INCA, que desde 1989 ocupava a coordenação do PNCT, estabeleceu-se como o principal órgão na articulação e coordenação da política brasileira de controle do tabaco. A partir de 1996, as parcerias com organizações não governamentais e as secretarias municipais e estaduais de saúde foram fundamentais para a internalização das medidas de controle do tabagismo no SUS 34. O protagonismo do INCA como Secretaria Executiva da CONICQ reforça a sua importância para o controle do tabaco no Brasil.

A Anvisa também se destacou na estruturação da política. A partir de 2000, por meio da Gerência-Geral de Produtos Derivados do Tabaco, a Agência passou a atuar em uma temática até então desconhecida do campo da vigilância 34 . Apesar da sua legitimidade e importância para a proteção dos interesses da coletividade, a atuação da Anvisa tem sido questionada judicialmente pela indústria do fumo. $\mathrm{O}$ apoio da sociedade e dos três Poderes é fundamental para que a regulação de produtos do tabaco no Brasil não seja comprometida 35,36,37.

Um terceiro fator refere-se ao importante papel da sociedade civil a partir de 2003. A participação de organizações não governamentais, com destaque para as sociedades médicas e a ACT, foi imprescindível para a ratificação da CQCT-OMS pelo Brasil e tem sido fundamental para a implementação da PNCT ao desempenhar ações envolvendo pesquisas, capacitações, campanhas e advocacy 5,38.

Por fim, ressalta-se a rejeição social ao tabaco, consolidada a partir dos anos 2000. A consciência social sobre a inconveniência do acesso ilimitado ao consumo do tabaco, aliada às regulações jurídicas, tem contribuído para reforçar o tabagismo como uma prática antissocial 39.

Esses fatores foram determinantes para a superação das dificuldades enfrentadas pela PNCT. Malta et al. 40, a partir de um balanço da Política Nacional de Promoção da Saúde (PNPS), de 2006 a 2014, ressaltaram as conquistas envolvendo o controle do tabaco no âmbito da gestão, financiamento, regulação, articulação intersetorial, promoção de saúde no território, mobilização social e comunicação. A redefinição da PNPS em 2014 manteve o tema como uma de suas prioridades 41.

Além disso, vale destacar a evolução das estratégias destinadas ao controle do tabaco previstas no Plano de Ações Estratégicas para o Enfrentamento das Doenças Crônicas Não Transmissiveis (DNCT) no Brasil: 20011-2022 42. Entre 2011 e 2015, ressaltam-se os avanços na regulação dos produtos derivados do tabaco, nas legislações referentes à promoção de ambientes livres de fumo, às advertências nos maços e aos preços e impostos de cigarros, na oferta do tratamento do tabagismo no SUS e nas campanhas 23.

Apesar dos avanços do controle do tabaco no Brasil, o tabagismo continua sendo um grave problema de saúde pública no país, apresentando números impactantes relacionados à morbidade, mortalidade e custos gerados para o SUS 43 . Nesse contexto, alguns desafios da PNCT merecem ser destacados.

A necessidade de diversificação em áreas plantadas de fumo é sustentada por pesquisas que evidenciam o endividamento gerado pelo sistema integrado de produção do tabaco 44,45 , os danos à saúde do agricultor e os impactos ambientais da fumicultura 46,47. Além disso, a queda internacional da demanda por tabaco tem reduzido o faturamento da fumicultura e o número de famílias envolvidas com a atividade ${ }^{48,49}$. No entanto, vários elementos dificultam a diversificação: as pequenas propriedades, o ciclo ininterrupto do cultivo do fumo, o baixo interesse político associado à relevância da fumicultura na economia local, as dificuldades na comercialização dos novos cultivos, o risco de diminuição na obtenção de lucro e a carência de estudos que apontem a viabilidade econômica de culturas alternativas 50,51. Nesse sentido, torna-se fundamental o fortalecimento da articulação dos atores envolvidos com esse tema, como o Ministério do Desenvolvimento Agrário, Ministério da Agricultura, Pecuária e Abastecimento e estados e municípios produtores, para que o Programa Nacional de Diversificação em Áreas Cultivadas com Tabaco possa garantir a transição para outros cultivos sem prejuízos para o agricultor.

Significativos esforços também são necessários para avanços no combate ao comércio ilícito de cigarros. Estudos recomendam maior rigor no cumprimento das leis e o fortalecimento da articulação entre Brasil e Paraguai para a adoção de medidas que reduzam o contrabando de cigarros 52,53. Além da importância da implementação integral das medidas previstas no artigo 15 da CQCT-OMS (comércio ilícito de produtos de tabaco) e da equiparação dos preços e impostos de cigarros no Brasil e em seus países vizinhos, a ratificação do Protocolo para Eliminar o Comércio Ilícito de Produtos 
de Tabaco pelo país é necessária para a sustentação legal e política do combate ao comércio ilícito 52 .

Por fim, a proteção da PNCT da interferência da indústria do fumo é um desafio. Entre as táticas a serem combatidas, destacam-se as doações e patrocínio da indústria 54 e a expansão de novos produtos, como o cigarro eletrônico e o narguilé 55 . O envolvimento das três esferas de governo é fundamental para conter a influência de grupos de interesses contrários à saúde pública 56.

Consideram-se limitações do estudo a impossibilidade de aprofundamento de todos os aspectos relacionados à política, a dificuldade de acesso a atores da cadeia produtiva do fumo e a limitada participação dos pesquisadores nas arenas da política.

\section{Conclusões}

O sucesso da política brasileira de controle do tabaco entre 1986 e 2016 é evidenciado pela expressiva redução da prevalência de fumantes nesse período. A consolidação da rejeição social ao tabagismo, a estruturação governamental da política, a participação da sociedade civil e o prestígio do Brasil no cenário internacional foram fundamentais para a institucionalidade do controle do tabaco no país. Destaque-se a relevância da interação entre elementos relacionados ao conteúdo da política, ao processo político e ao contexto nacional e internacional.

O Brasil foi pioneiro na adoção de uma série de iniciativas e contribuiu para as negociações da CQCT-OMS. A partir da assinatura do tratado internacional, conflitos relacionados aos interesses econômicos ficaram mais evidentes, retardaram sua ratificação e impuseram dificuldades à implementação de medidas de controle do tabaco no país. Porém, a CQCT-OMS representou um novo patamar para a luta dos atores comprometidos com o controle do tabagismo, passando a dar sustentação e a orientar a política nacional. O Brasil destaca-se na implementação de medidas de controle do tabaco no mundo, juntamente com países como Austrália, Canadá, Panamá, Turquia e Uruguai 57.

Além da permanência da PNCT na agenda governamental, da expansão da base de apoio à política e do financiamento adequado para as ações, destacam-se desafios relacionados à diversificação em áreas plantadas de fumo, ao combate ao comércio ilícito de cigarros e à interferência da indústria do fumo na política. Recomendam-se estudos que analisem a complexidade de cada desafio, a fim de gerar evidências que possam colaborar para o seu enfrentamento com vistas à consolidação e sustentabilidade da política em médio e longo prazos. 


\section{Colaboradores}

L. H. Portes, C. V. Machado e S. R. B. Turci contribuíram na concepção e projeto do artigo, análise e interpretação dos dados; redação do artigo e revisão crítica relevante do conteúdo intelectual; aprovação final da versão a ser publicada; e são responsáveis por todos os aspectos do trabalho na garantia da exatidão e integridade de qualquer parte da obra.

\section{Agradecimentos}

Os autores agradecem pelo apoio financeiro da ENSP/Fiocruz e do Programa de Excelência Acadêmica da Capes, para a realização do estudo.

\section{Referências}

1. Samet JM. Tobacco smoking: the leading cause of preventable disease worldwide. Thorac Surg Clin 2013; 23:103-12.

2. Comissão Nacional para Implementação da Convenção-Quadro para controle do Tabaco, Instituto Nacional de Câncer José Alencar Gomes da Silva. Política Nacional de Controle do Tabaco: relatório de gestão e progresso 2011-2012. Rio de Janeiro: Instituto Nacional de Câncer José Alencar Gomes da Silva; 2014.

3. Teixeira L, Jaques T. Legislação e controle do tabaco no Brasil entre o final do século XX e início do XXI. Rev Bras Cancerol 2011; 57:295-304.

4. Araújo AJ. Seção I - tabagismo como epidemia. In: Araújo AJ, organizador. Manual de condutas e práticas em tabagismo. Rio de Janeiro: Gen Editorial; 2012. p. 3-12.

5. da Costa e Silva VL, Pantani D, Andreis M, Sparks R, Pinsky I. Bridging the gap between science and public health: taking advantage of tobacco control experience in Brazil to inform policies to counter risk factors for non-communicable diseases. Addict 2013; 108:1360-6.

6. Freeman R, Moran M. Reforming health care in Europe. West Eur Polit 23:35-59.

7. Ham C, Hill MJ. The policy process in the modern capitalist state. New York: Harvester Wheatsheaf; 1993.

8. Skocpol T. Why I am an historical institutionalist. Polity 1995; 28:103-6.

9. Paim J, Travassos C, Almeida C, Bahia L, Macinko J. The Brazilian health system: history, advances, and challenges. Lancet 2011; 377:1778-97.

10. Brasil. Lei no 9.294 de 15 de julho de 1996. Dispõe sobre as restrições ao uso e à propaganda de produtos fumígeros, bebidas alcoólicas, medicamentos, terapias e defensivos agrícolas, nos termos do $\$ 4$ o do art. 220 da Constituição Federal. Diário Oficial da União 1996; 16 jul.

11. Brasil. Lei Federal no 10.167 , de 27 de dezembro de 2000. Altera dispositivos da Lei no 9.294, de 15 de julho de 1996, que dispõe sobre as restrições ao uso e à propaganda de produtos fumígenos, bebidas alcoólicas, medicamentos, terapias e defensivos agrícolas. Diário Ofical da União 2000; $28 \mathrm{dez}$.

12. Ministério da Saúde. Portaria no 1.035, de 31 de maio de 2004. Diário Oficial da União 2004; 1 jun.

13. World Health Organization. Protocol to eliminate illicit trade in tobacco products. http:// www.who.int/fctc/protocol/en/ (acessado em 02/Fev/2017).

14. World Health Organization. Global action plan for the prevention and control of noncommunicable diseases: 20132020. http://apps.who.int/iris/bitstre am/10665/94384/1/9789241506236_eng.pdf (acessado em 17/Abr/2017).

15. Brasil. Lei no 12.546 , de 14 de dezembro de 2011. Diário Oficial da União 2011; 15 dez. 
16. Brasil. Decreto no 8.262 , de 31 de maio de 2014. Altera o Decreto no 2.018 , de 1o de outubro de 1996, que regulamenta a Lei no 9.294 , de 15 de julho de 1996. Diário Oficial da União 2014; 2 jun.

17. Supremo Tribunal Federal. Pautas de julgamento. http://www.stf.jus.br/portal/pau ta/verTema.asp?id=70527 (acessado em 14/ Abr/2017).

18. Aviso da Ministra da Casa Civil ao Senador Heráclito Fortes. Aviso no 1.151/2005. http:// www.al.sp.gov.br/repositorio/legislacao/coleta nea/15_5_28.htm (acessado em 02/Fev/2017).

19. World Health Organization. Economically sustainable alternatives to tobacco growing (in relation to Articles 17 and 18 of the WHO Framework Convention on Tobacco Control). Conference of the Parties to the WHO Framework Convention on Tobacco Control. Fifth session, 2012. http://apps.who.int/gb/fctc/ PDF/cop5/FCTC_COP5_10-en.pdf (acessado em 13/Abr/2017).

20. Secretaria Especial de Agricultura Familiar e do Desenvolvimento Agrário. Programa Nacional de Diversificação em Áreas Cultivadas com Tabaco. http://www.mda.gov.br/sitemda/ secretaria/saf-projetosespeciais/programa-na cional-de-diversifica\%C3\%A7\%C3\%A3o-em\% $3 \%$ A1reas-cultivadas-com-tabaco (acessado em 13/Abr/2017).

21. Ministério da Agricultura, Pecuária e Abastecimento. Câmara Setorial da Cadeia Produtiva do Fumo. http://www.agricultura.gov.br/as suntos/camaras-setoriais-tematicas/camarassetoriais-1/tabaco (acessado em 13/Abr/2017).

22. Monteiro CA, Cavalcante TM, Moura EC, Claro RM, Szwarcwald CL. Population-based evidence of a strong decline in the prevalence of smokers in Brazil (1989-2003). Bull World Health Organ 2007; 85:527-34.

23. Malta DC, Oliveira TP, Santos MAS, Andrade SSCA, Silva MMA. Avanços do plano de ações estratégicas para o enfrentamento das doenças crônicas não transmissíveis no Brasil, 20112015. Epidemiol Serv Saúde 2016; 25:373-90.

24. Malta DC, Oliveira TP, Luz M, Stopa SR, da Silva Junior JB, Dos Reis AA. Smoking trend indicators in Brazilian capitals, 2006-2013. Ciênc Saúde Coletiva 2015; 20:631-40.

25. Szklo AS, Almeida LM, Figueiredo VC, Autran M, Malta D, Caixeta R, et al. A snapshot of the striking decrease in cigarette smoking prevalence in Brazil between 1989 and 2008. Prev Med 2012; 54:162-7.

26. Levy D, de Almeida LM, Szklo A. The Brazil SimSmoke policy simulation model: the effect of strong tobacco control policies on smoking prevalence and smoking-attributable deaths in a middle income nation. PLoS Med 2012; 9:e1001336.

27. Szklo AS, Souza MC, Szklo M, Almeida LM. Smokers in Brazil: who are they? Tob Control 2016; 25:564-70.

28. Machado CV, Baptista TWF, Lima LD. Políticas de saúde no Brasil: continuidades e mudanças. Rio de Janeiro: Editora Fiocruz; 2012.
29. Wipfli H, Stillman F, Tamplin S, Costa e Silva VL, Yach D, Samet J. Achieving the Framework Convention on Tobacco Control's potential by investing in national capacity. Tob Control 2004; 13:433-7.

30. Lee K, Chagas LC, Novotny TE. Brazil and the Framework Convention on Tobacco Control: global health diplomacy as soft power. PLoS Med 2010; 7:e1000232.

31. Saldanha PMC. Convenção do tabaco na OMS: gênese e papel da presidência brasileira nas negociações. Brasília: Fundação Alexandre de Gusmão; 2015.

32. Romero L, Costa e Silva V. 23 anos de controle do tabaco no Brasil: a atualidade do Programa Nacional de Combate ao Fumo de 1988. Rev Bras Cancerol 2011; 57:305-14.

33. Bialous S, Costa e Silva VL, Drope J, Lencucha R, McGrady B, Richter AP. The political economy of tobacco control in Brazil: protecting public health in a complex policy environment. Rio de Janeiro: Centro de Estudos sobre Tabaco e Saúde, Escola Nacional de Saúde Pública Sergio Arouca, Fundação Oswaldo Cruz/Atlanta: American Cancer Society; 2014.

34. Instituto Nacional de Câncer; Pan American Health Organization. Global adult tobacco survey: Brazil report. Rio de Janeiro: Instituto Nacional de Câncer; 2010.

35. Veiga EM, Pannunzio MIM, Cunha TR, Garrafa $V$. A legitimidade da intervenção estatal na publicidade de produtos sujeitos à vigilância sanitária. Rev Direito Sanit 2011; 12:91-111.

36. Turci SRB, Figueiredo VC, Silva VLC. A regulação de aditivos que conferem sabor e aroma aos produtos derivados do tabaco no Brasil. Cadernos Ibero-Americanos de Direito Sanitário 2014; 3:44-67.

37. Silva VA. Anvisa e o controle do tabagismo. Revista de Direito Administrativo 2015; 268:295-332.

38. Silva LCC, Araújo AJ, Queiroz AMD, Sales MPU, Castellano MVCO; Comissão de Tabagismo da SBPT. Smoking control: challenges and achievements. J Bras Pneumol 2016; 42:290-8.

39. Gomes PGVS. Convenção-quadro para o controle do tabaco: políticas públicas de implementação [Tese de Doutorado]. São Paulo: Universidade de São Paulo; 2014.

40. Malta DC, Silva MMA, Albuquerque GM, Lima CM, Cavalcante T, Jaime PC, et al. A implementação das prioridades da Política Nacional de Promoção da Saúde, um balanço, 2006 a 2014. Ciênc Saúde Coletiva 2014; 19:4301-12.

41. Secretaria de Atenção à Saúde; Secretaria de Vigilância em Saúde, Ministério da Saúde. Política Nacional de Promoção da Saúde (PNPS): revisão da Portaria MS/GM no 687, de 30 de março de 2006. http://bvsms.saude.gov.br/ bvs/publicacoes/pnps_revisao_portaria_687. pdf (acessado em 26/Dez/2016).

42. Ministério da Saúde. Plano de ações estratégicas para o enfrentamento das doenças crônicas não transmissíveis (DCNT) no Brasil: 2011 2022. Brasília: Ministério da Saúde; 2011. (Série B. Textos Básicos de Saúde). 
43. Pinto MT, Pichon-Riviere A, Bardach A. Estimativa da carga do tabagismo no Brasil: mortalidade, morbidade e custos. Cad Saúde Pública 2015 ; 31:1283-97.

44. Bonato AA. Desafios e potencialidades para a diversificação na agricultura familiar produtora de tabaco. http://www.mda.gov.br/sitemda/ sites/sitemda/files/user_arquivos_64/pageflip-2583697-4429081-lt_Desafios_e_Poten ciali-1710093.pdf (acessado em 20/Jan/2017).

45. Riquinho DL, Hennington EA. Sistema integrado de produção do tabaco: saúde, trabalho e condições de vida de trabalhadores rurais no Sul do Brasil. Cad Saúde Pública 2016; 32:e00072415.

46. Novotny TE, Bialous SA, Burt L, Curtis C, da Costa VL, Iqtidar SU, et al. The environmental and health impacts of tobacco agriculture, cigarette manufacture and consumption. Bull World Health Organ 2015; 93:877-80.

47. Riquinho DL, Hennington EA. Health, environment and working conditions in tobacco cultivation: a review of the literature. Ciênc Saúde Coletiva 2012; 17:1587-600.

48. Associação dos Fumicultores do Brasil. Fumicultura no Brasil. http://www.afubra.com. br/fumicultura-brasil.html (acessado em 27/ Dez/2016).

49. Instituto Nacional de Câncer José Alencar Gomes da Silva. Notas técnicas para o controle do tabagismo: a importância e a urgência da diversificação de produção em áreas que produzem tabaco no Brasil. Rio de Janeiro: Instituto Nacional de Câncer José Alencar Gomes da Silva; 2014

50. Vargas MA, Oliveira BF. Estratégias de diversificação em áreas de cultivo de tabaco no Vale do Rio Pardo: uma análise comparativa. Revista de Economia e Sociologia Rural 2012; 50:157-74.

51. Riquinho DL, Hennington EA. Diversificação agrícola em localidade rural do Sul do Brasil: reflexões e alternativas de cumprimento da Convenção-Quadro para o controle do tabaco. Physis (Rio J.) 2014; 24:183-207.

52. Iglesias RM, Szklo AS, Souza MC, Almeida LM. Estimating the size of illicit tobacco consumption in Brazil: findings from the global adult tobacco survey. Tob Control 2017; 26:53-9.
53. Iglesias RM. Increasing excise taxes in the presence of an illegal cigarette market: the 2011 Brazil tobacco tax reform. Rev Panam Salud Pública 2016; 40:243-9.

54. Szklo AS, Iglesias RM, Souza MC, Szklo M, Cavalcante TM, de Almeida LM. Understanding the relationship between sales of legal cigarettes and deaths: a case-study in Brazil. Prev Med 2017; 94:55-9.

55. Bialous SA, Peeters S. A brief overview of the tobacco industry in the last 20 years. Tob Control 2012; 21:92-4.

56. Bialous SA, Presman S, Gigliotti A, Muggli M, Hurt R. A resposta da indústria do tabaco à criação de espaços livres de fumo no Brasil. http:// iris.paho.org/xmlui/handle/123456789/9696 (acessado em 28/Dez/2016).

57. World Health Organization. WHO report on the global tobacco epidemic, 2015: raising taxes on tobacco. Geneva: World Health Organization; 2015.

58. Figueiredo VC. Um panorama do tabagismo em 16 capitais brasileiras e Distrito Federal: tendências e heterogeneidades [Tese de Doutorado]. Rio de Janeiro: Instituto de Medicina Social, Universidade do Estado do Rio de Janeiro; 2007.

59. Instituto Brasileiro de Geografia e Estatística. Pesquisa Nacional de Saúde, 2013: percepção do estado de saúde, estilos de vida e doenças crônicas: Brasil, grandes regiões e Unidades da Federação. Rio de Janeiro: Instituto Brasileiro de Geografia e Estatística; 2014.

60. Instituto Nacional de Câncer José Alencar Gomes da Silva. Abordagem e tratamento do tabagismo na rede SUS de 2005 a 2013. http:// www2.inca.gov.br/wps/wcm/connect/7605f c004fe6c76ebbf3ff76651c600b/14-Relat\% C3\%B3rio+de+Gest\%C3\%A3o+e+Progres so+2013-2014.pdf? MOD =AJPERES\&CA CHEID $=7605 \mathrm{fc} 004 \mathrm{fe} 6 \mathrm{c} 76 \mathrm{ebbf3ff76651c600b}$ (acessado em 08/Jan/2018). 


\section{Abstract}

This study analyzes Brazil's tobacco control policy from 1986 to 2016, seeking to describe the policy's history and discuss its achievements, limits, and challenges. The study adopted a political economics approach and contributions from public policy analysis. Data were based on a search of the literature, documents, and secondary sources and semi-structured interviews with stakeholders involved in the policy. Factors related to the domestic and international contexts, the political process, and the policy's content influenced the institutional characteristics of tobacco control in the country. The study emphasizes the consolidation of Brazil's social rejection of smoking, government structuring of the policy, action by civil society, and Brazil's prestige in the international scenario. Intersector tobacco control measures like price and tax increases on cigarettes, the promotion of smokefree environments, and the enforcement of health warnings contributed to the important reduction in prevalence of smoking. Implementation of the World Health Organization Framework Convention on Tobacco Control in Brazil, beginning in 2006, contributed to the expansion and consolidation of the national policy. However, tobaccorelated economic interests limited the implementation of some strategic measures. The challenges feature the medium-and long-term sustainability of tobacco control and the solution to barriers involving crop diversification on current tobaccogrowing areas, the fight against the illegal cigarette trade, and interference in the policy by the tobacco industry.

Tobacco; National Program of Tobacco Control; Public Health Policy

\section{Resumen}

El estudio analiza la política brasileña de control al tabaco entre 1986 y 2016, procurando determinar la trayectoria de la politica en este sentido, además de discutir sus avances, límites y desafíos. Se adoptaron la perspectiva de la economía politica y contribuciones dentro del marco referencial del análisis a las políticas públicas. Se realizó un análisis bibliográfico, documental, de datos secundarios y de entrevistas semiestructuradas con actores involucrados en la politica. Los factores relacionados con el contexto nacional e internacional, proceso político y contenido de la política influenciaron la institucionalidad del control al tabaco en el país. Se resaltan la consolidación del rechazo social al tabaquismo, la estructuración gubernamental de la politica, la actuación de la sociedad civil y el prestigio de Brasil en el escenario internacional. Las medidas intersectoriales de control al tabaco, como el aumento de precios e impuestos de cigarrillos, la promoción de ambientes libres de tabaco y la adopción de advertencias sobre los perjuicios del tabaquismo contribuyeron a una expresiva reducción de la prevalencia de fumadores durante el período. La implementación de la Convención-Marco para el Control del Tabaco de la Organización Mundial de la Salud, en Brasil, a partir de 2006, contribuyó a la expansión y consolidación de la política nacional. No obstante, los intereses económicos, relacionados con el tabaco, limitaron la implementación de algunas acciones estratégicas. Entre los desafíos, se destacan la sostenibilidad del control al tabaco a medio y largo plazo y la superación de las barreras relacionadas con la diversificación en áreas plantadas con tabaco, el combate al comercio ilícito de cigarrillos y la interferencia de la industria del tabaco en la politica.

Tabaco; Programa Nacional de Control del Tabaquismo; Políticas Públicas de Salud
Recebido em 03/Fev/2017

Versão final reapresentada em 17/Abr/2017 Aprovado em 17/Jul/2017 